\title{
CAMPESINATO E REFORMA AGRÁRIA: UM DEBATE CONTEMPORÂNEO
}

\author{
Everton Nogueira Silva \\ Mestre em Economia Rural / Universidade Federal do Ceará \\ enogueirasilva@hotmail.com
}

\section{Renata Firmino do Amaral}

Mestre em Economia Rural/ Universidade Federal do Ceará

amaralrenataf@gmail.com

\author{
Harine Matos Maciel \\ Mestre em Economia Rural/ Universidade Federal do Ceará \\ harinematos@yahoo.com.br
}

\section{RESUMO}

As discussões sobre o campesinato e a reforma agrária seguem uma lógica histórica de exclusão social e política no Brasil. Os órgãos e as novas políticas agrárias buscam incluir o trabalhador rural, com ou sem terra, dentro da lógica conceitual da agricultura familiar através de ações que atendam aos parâmetros exigidos pelo capitalismo moderno, não havendo um incentivo maior para a construção de um projeto social que atenda as reais necessidades do modo de vida camponês. Neste artigo será aberto um espaço de discussão à necessidade de uma reforma agrária em que o território ou o fator terra não seja o principal aspecto que fundamenta a necessidade da inclusão camponesa em um projeto rural mais amplo.

Palavras-chave: Camponês; Reforma agrária; Agricultura familiar

\begin{abstract}
Discussions on the peasantry and agrarian reform follows a historical logic of social and political exclusion in Brazil. The organs and the new agrarian policies seek to include rural workers, with or without land, within the conceptual logic of family farming through actions that meet the parameters required by modern capitalism, there is no greater incentive for building a social project meets the real needs of the peasant way of life. This article will open a space for discussion of the need for land reform in the territory or the land factor is not the main aspect that underlies the need for peasant inclusion in a broader rural project.
\end{abstract}

Keywords: peasant, agrarian reform, family agriculture

\section{INTRODUÇÃO}

A discussão da reforma agrária perpassa por todo um panorama de construção histórica da sociedade brasileira. Para o rural destaca-se que no Brasil colônia, houve um período em que a terra era concedida aqueles "homens bons" que aplicavam uma agricultura baseada na monocultura da cana-de-açúcar e no trabalho escravo (período que vai do século XVI ao XVIII). No século XIX, em especial, entra em cena o café para exportação, porém o regime latifúndio-escravocrata (depois substituído pela exploração do trabalho do imigrante) permanece o mesmo, havendo a legitimação dessa forma de produção na "Lei de Terras" de 1850 (IGLÉSIAS et.al, 2004). Chega-se ao século XX e a política de modernização do setor agrícola prioriza as grandes empresas rurais, geradoras de "emprego" para a massa "ociosa" rural. Quem domina o cenário são os parâmetros produtividade e maximização de lucro acarretando para o rural: baixo nível de salários pago aos camponeses, afirmação do latifúndio e o cultivo baseado na monocultura da soja, do algodão, do milho, dentre outros. Hoje, para o camponês, permanecesse um projeto e/ou o sistema de produção agrícola denominado o "mais do mesmo", reproduzindo a política de inclusão da agricultura nas plataformas de produção agroexportadora e agroindustrial, não havendo um espaço ampla para o processo de 
democratização do acesso a terra e/ou a projetos que atendam aos anseios para a consolidação da classe trabalhadora camponesa.

A necessidade de um programa efetivo de reforma agrária no Brasil a muito tempo vem sendo discutida nas mais diversas esferas sociais e políticas brasileiras. Alguns consideram que já houve a reforma agrária e que o camponês deve está incluso dentro de um projeto maior que o torne participante do mercado dentro de uma visão de agricultura familiar tendo por parceira o Governo Federal em seus programas de fomento. Já alguns acadêmicos e representantes de lutas e movimentos sociais, como o MST, veem que não há a inclusão plena do camponês no processo e/ou projeto de reforma agrária brasileiro, sendo um sujeito passivo no processo de decisão política, pois, a própria liderança dos movimentos sociais rurais não representam na maioria dos casos a emergência da real necessidade social camponesa.

Esse artigo tem por iniciativa expor a problemática da reforma agrária não só por uma visão da reforma baseada no simples acesso ao fator terra e/ou território, e sim abrir um espaço para a discussão de um projeto maior para o camponês a partir de um levantamento bibliográfico pautado no entendimento de todo um processo de luta da classe camponesa brasileira.

\section{RAÍZES HISTÓRICAS DA DISCUSSÃO AGRÁRIA BRASILEIRA - A QUESTÃO DA TERRA}

[...] se as terras do país estivessem livres, os camponeses, assim como os homens livres que aqui chegassem, necessariamente, iriam se estabelecer nos territórios ainda não ocupados pelas grandes fazendas. Ao mesmo tempo as fazendas ficariam despovoadas sem possibilidades de expansão, sem a força de trabalho. Por isso, a elite dominante instituiu o cativeiro da terra, como forma de subjugar o trabalho dos camponeses sem-terra e dos homens livres que fossem atraídos para o Brasil (OLIVEIRA, 2012).

A questão da reforma agrária brasileira atual ainda reproduz os resquícios do modo de produção e reprodução do sistema colonial português (1500-1822) que tinha por pilar de sustentação a exploração dos recursos ambientais em grandes concessões de terras denominadas de capitanias hereditárias. Boris Fausto em seu livro intitulado "História do Brasil" demonstra que o sistema de capitanias hereditárias e sesmarias reproduz o modo de produção definido como "plantation". O modo de produção "plantation" baseia-se na grande propriedade rural com o cultivo de um gênero destinado à exportação e predomínio do trabalho escravo.

Boris Fausto destaca que a partir dos estudos realizados por Caio Prado Júnior o modo de produção "plantation" passa a ser mencionado como a forma básica de produção da propriedade rural colonial brasileira. Mas, ao longo do tempo autores como Francisco Carlos Teixeira da Silva e Ciro Flamarion Cardoso passam a questionar o modelo clássico de "plantation" brasileiro. Teixeira considera que o modelo denominado "plantacionista" - monocultura da cana de açúcar - era assumido pela classe dominante colonial e a Coroa Portuguesa tinha a preocupação em estimular também a produção dos demais gêneros alimentícios para que houvesse a garantia da segurança alimentar na Colônia. Já Cardoso destaca que a obsessão para com o conceito de "plantation" acabava por deixar de lado alguns fatores importantes da complexa realidade econômica e social brasileira para o período colonial havendo a redução da estrutura social a senhores em um polo e escravos em outro, esquecendo-se a importância do trabalho do homem branco "livre", ou seja do pequeno proprietário rural, o camponês.

Quando se fala em camponês tenta-se se estabelecer uma conexão com a base teórica ao regime camponês europeu marcado pela relação feudal com relação ao uso da terra - a chamada copropriedade - tão amplamente aplicada em regimes de governos totalitários. No caso brasileiro, Stédile (2013) destaca que: 
Notem bem, a propriedade da terra no Brasil, desde que foi distribuída em sesmarias, no século XVI, pelos colonizadores portugueses, sempre foi uma propriedade alodial, quer dizer, livre de encargos feudais; quem adquiria essa terra por via de sesmaria ou, depois, de compra não ficava vassalo de ninguém, não era um homem dependente, não era obrigado a pagar os inúmeros tributos feudais que na Europa constituíam o chamado complexum feudale.

Nota-se que as terras brasileiras eram passíveis de acesso a quem tinha maiores recursos financeiros marcada pela atividade mercantil. Stédile (2013) também evidencia em seu manuscrito que com o fim da escravidão os grandes proprietários rurais produtores até então de cana de açúcar e café para exportação não tinham mais a necessidade de dispender uma quantia substancial na compra de escravos sendo direcionado os recursos financeiros direcionados a compra de mais terra, ou seja, "o fundamental para o domínio econômico passou a ser o domínio da terra [...] dominar a terra passou a significar dominar a própria economia".

Apesar das críticas mencionadas anteriormente, Prado Junior ressalta em seu livro História Econômica do Brasil que existirá uma classe embrionária intermediária entre o grande proprietário e o escravo. A classe embrionária se constituía por pequenos proprietários de terra e suas famílias, as vezes com auxiliares e raramente com escravos. Não era dado o direito aos "homens livres" e suas famílias de participarem do sistema de doação de terras. A prática mais comumente realizada pelos camponeses era o de estabelecer suas propriedades em áreas localizadas: nas brechas entre as grandes plantações e em terras consideradas de ninguém com a presença de solos de baixa fertilidade e distante de grandes núcleos urbanos; terras cedidas de grandes plantações; áreas internas abandonadas das sesmarias e em latifúndios semiexplorados. Ressalta-se que que não havia uma forma clara de lei que amparasse judicialmente o direito da pequena propriedade rural estando a posse garantida pela ocupação e o trabalho (GERMANI, 2006). Sob esses aspectos Cirne Lima apud Guimarães (1977, p.114) observa que:

Apoderar-se das terras devolutas e cultivá-las [...] torna-se coisa corrente entre os nossos colonizadores e tais proporções essa prática atingiu que pode, com o decorrer dos anos, vir a ser considerada como modo legítimo de aquisição do domínio, paralelamente a princípio e, após, em substituição ao nosso tão desvirtuado regime das sesmarias. [...] A sesmaria é o latifúndio, inaccessível ao lavrador sem recursos. A posse é, pelo contrário - ao menos nos seus primórdios - a pequena propriedade agrícola, criada pela necessidade, na ausência de providência administrativa sobre a sorte do colono livre e vitoriosamente firmada pela ocupação.

Sob a temática de uma legislação fundiária, Lima (1988) destaca que no período colonial havia um grande número de avisos, resoluções administrativas, cartas de doação, forais e textos das Ordenações, todos sendo instrumentos e dispositivos legais, porém ensejando uma legislação fragmentada, nem sempre coesa, revogada e reafirmada as situações e circunstâncias do tempo tendo a base de regime jurídico para a terra à sesmaria.

Quando se pensa em um sistema jurídico ou lei específica que regula o acesso à terra, aos grandes e pequenos proprietários rurais, destaca-se a "Lei de Terras" de 1850 como uma plataforma de empoderamento do Estado em relação ao acesso e direito a terra. Naquele momento já havia uma emergência por parte da sociedade em procurar regular a questão da terra pois ela passa a ser uma forma de riqueza não sendo mais interessante ao Estado ainda adotar o sistema de concessão das sesmarias que concedia a terra aos homens bons de forma gratuita. Segundo Garcia (1958) as concessões de terras em sesmarias foram suspensas às vésperas da proclamação da independência até a convocação da Assembleia Geral Constituinte como uma medida que buscava atenuar a multiplicação de abusos e escândalos no meio rural. Graziano da Silva (1980, p.25-26) destaca que a "Lei de Terras" significou na prática a possibilidade de fechamento para uma via mais democrática de desenvolvimento capitalista na medida que limitou o acesso à terra a vastos setores da população. Já Lima (2002) destaca a promoção de mudanças de forma significativa na concepção da propriedade da terra com a Lei de Terras passando o poder de concessão simples e legítimo das mãos do 
imperador Dom Pedro II - distribuição de terras pelo prestígio social do beneficiário - para as mãos do mercado que controlaria as novas aquisições a partir do poder econômico de seu comprador. Porém sobre a tutela do Estado ficou a responsabilidade de gerir e legislar sobre as terras devolutas.

O fim do sistema sesmarial e a nova plataforma de acesso à terra, o mercado - modernização do setor agrário - não conseguiu estancar a questão do apossamento das terras públicas em associação à interesses rurais dominantes ao longo dos séculos. Não menos importante, o apossamento tornou-se também uma ferramenta para o ingresso do camponês no meio agrário, isto é, como definiu Germani (2006), uma ocupação extralegal que serviu de instrumento para a formação da pequena propriedade no Brasil que ao longo de décadas vem sustentando uma luta contínua pelo o direito ao acesso à terra como modo de produção e reprodução da agricultura de raiz "familiar" conforme veremos adiante.

\section{RELAÇÕES DE PODER E TRABALHO NO RURAL - O CASO BRASIL}

Desde o início da colonização, a terra, as técnicas e a mão-de-obra agrícola foram concentradas para gerar riquezas no mercado internacional e não para elevar o nível alimentar da população. Já havia uma visão do propósito produtivo desvinculado das necessidades sociais. A economia agrícola brasileira pouco mudou em termos de propósito e racionalidade, orientando-se basicamente para a exportação. Mudou a forma como os agentes passaram a trabalhar. Os modernizadores arcaicos continuam, entretanto, defendendo como moderna uma lógica agrícola de quinhentos anos (BUARQUE, 1991).

A partir da segunda metade do século XIX o Brasil se ver envolto em mudanças políticas e sociais que mudariam principalmente a conjuntura econômica brasileira. A Lei de Terras de 1850 marca a fase inicial nas mudanças emergentes e necessárias para "ampliar" o acesso a terra. Já com relação ao fator trabalho para o meio rural brasileiro, destaca-se a assinatura da Lei Áurea de 1888 que acaba com o "câncer" do sistema escravocrata. Aquino (1986) ressalta que a agricultura brasileira, para o período colonial, tinha formas de produção agrícola classificadas como rudimentares - ressalta-se que para esse período o nível de industrialização não era completo no Brasil - e que se somando ao fato da escassez de mão-de-obra escrava o rural brasileiro entraria em colapso. Mas, para o mesmo período, historiadores como Furtado (1959), Holanda (1976) e Prado Jr. (1978) evidenciam em seus estudos que a partir da segunda metade do século XIX ao lado da agricultura baseado no sistema latifundiário de monocultivo, se inicia uma agricultura de aspecto mais social baseada na propriedade familiar dos imigrantes (substituição do sistema escravocrata pela mão de obra assalariada nas propriedades rurais), de pequenas parcelas de alforriados e de descendentes de portugueses. Outro aspecto relevante sobre o campesinato brasileiro evidencia-se em estudos como o de Silva et. al (1983) que identifica uma difícil caracterização do setor camponês brasileiro, onde não há uma "segmentação nítida" como ocorre com as comunidades indígenas peruanas ou com os reformados chilenos. A dificuldade de classificação do camponês no Brasil ocorre por o país apresentar uma grande área territorial com contrastes de configurações regionais e pôr o campesinato brasileiro tender a reproduzir os mais diversos setores produtivos agrícolas ao longo da história (SILVA et. al, 1983).

Com relação a "modernização da agricultura brasileira" para o período, o mesmo encontra-se amplamente em consonância para com o desenvolvimento econômico emergente - final do século XIX, início do século XX - tendo por base manutenção e/ou ampliação de novos mercados em núcleos urbanos recém constituídos e/ou em expansão. Sob a ótica do mercado, Lênin (1907) em seu livro intitulado "O Desenvolvimento do Capitalismo na Rússia", ressalta que:

[...] para o mercado, o que importa não é o bem-estar do produtor, mas os seu meios pecuniários disponíveis; o declínio do bem estar de um camponês patriarcal, que antes praticava uma economia predominantemente natural, é perfeitamente compatível com o aumento do volume dos recursos pecuniários em suas mãos, pois quanto mais esse camponês se arruína tanto é mais é forçado a recorrer à venda de sua força de trabalho e tanto maior é a parte dos meios de subsistência (mesmo que sejam os mais exíguos) que ele deve adquirir no mercado." 
Lênin em seus estudos realizados no começo do século XX já apontava que o fator mercado acaba por corroer todo um modo de produção e reprodução do modo de vida e de relações de trabalho camponês na Rússia. Por ser um estudo que expõe os problemas entre sistema capitalista emergente e sociedade camponesa russa, acaba por ser este estudo um norteador para o entendimento entre as relações do modo de vida camponês e mercado para toda e qualquer sociedade capitalista. De forma semelhante ao observado por Lênin, a sociedade camponesa brasileira sofreu e em destaque ainda sofre pelo processo capitalista que busca a fragmentação do modo de vida camponês. Ao longo do século XX torna-se uma necessidade o país gerar divisas pelo acumulo de capital para enfim se "modernizar". O acúmulo de capital está fundamentado na continuidade do sistema agrário latifundiário brasileiro tão amplamente difundido ao longo dos séculos. Müller (1989) evidencia que na busca de saldos positivos na balança comercial - menor nível de importação em relação ao nível de exportação - as políticas agrícolas das últimas décadas do século XX produziram efeitos distributivos perversos que culminou em um maior agravamento nas desigualdades sociais do país.

Abrindo uma discussão sobre o desenvolvimento do capitalismo brasileiro, Oliveira (2001) ressalta que a modernização da agricultura brasileira não segue uma tendência mundial de transformar o latifundiário em empresário capitalista e sim ocorre uma tendência contrária, grande parte do empresariado urbano e industrial ao longo do século XX tornam-se grandes proprietários de terra, pois terra além representa acumulação de capital e poder.

As técnicas camponesas de produção agrícola passam então a serem vistas como rudimentares, não inclusas no modo de produção monocultivo intensivo. Diante dos fatos, a exclusão - a partir do século XIX também permeia pelo o acesso as bases técnicas e tecnológicas relacionadas a qualquer tipo de assessoria para melhoria do cultivo de base familiar. Para Araújo (1998) "a tradição dos políticos, economistas e empresários é de valorizar a produção patronal para a exportação e desvalorizar a pequena produção agrícola familiar", pois elas fogem da esfera da relação do sistema capitalista (acúmulo de capital). Realizando uma análise das relações capitalistas e não capitalistas que permeia a ambiência rural, Silva (1976) observa que:

A simples aceitação da predominância de relações pré-capitalistas na agricultura é condição necessária, mas insuficiente, para análise da própria agricultura. É preciso ter sempre muito claro que tratamos do desenvolvimento do capitalismo: a noção de dominação indireta afirma que o fato fundamental é a subordinação das relações pré-capitalistas ao capital, dominante no conjunto da economia (o conjunto da economia, talvez valha explicitar o óbvio, inclui a agricultura). As relações pré-capitalistas só existem como formas subordinadas, mesmo se elas são predominantes na agricultura. Enfï, a análise das relações pré-capitalistas na agricultura é a análise do desenvolvimento do capitalismo na agricultura.

Nesse sentido, Paulo Freire em seu livro intitulado: Educação como Prática da Liberdade observa que todo o complexo do quadro sociocultural do meio agrário brasileiro sempre se beneficiou do baixo nível de escolaridade da população rural - manutenção do sistema de dependência do "pequeno agricultor" aos mandos e desmandos do "grande agricultor" - sendo colocado de lado todo o conhecimento da sociedade camponesa tradicional. O conhecimento deve romper o ciclo de dominação no meio agrário possibilitando construir um modo de vida digno que segundo Paulo Freire, deveria vir alicerçado nos direitos fundamentais do homem reproduzindo um modo de vida digno onde fosse possível viver e viver por opção em um modo de produção e reprodução camponês que tem na agricultura o seu único modo de vida que foi repassado por gerações através do saber empírico.

Diante do papel desafiador da educação como um dos suportes para mudança social do meio agrário brasileiro, evidencia-se nos cursos superiores de ciências agrárias em todo país (agronomia, zootecnia, pesca, dentre outros) um aspecto contraditório. As formações dos novos profissionais que deveriam atender a grande demanda social camponesa por informações técnicas e de mercado é direcionada quase que exclusivamente para a agricultura patronal, sendo excludente. Excludente também por rejeitar o conhecimento camponês tradicional que se encontra em equilíbrio com o modo de produção agroecológico. Neste sentido, Dias (2004) destaca: 


\begin{abstract}
Nos ambientes formativos das ciências agrárias, tanto em cursos técnicos e profissionalizantes quanto nos cursos de ensino superior há predominantemente uma visão histórica que insiste em reificar e superestimar os papéis do desenvolvimento tecnológico e da difusão de tecnologias para a solução dos mais diversos problemas e, consequentemente, para a promoção do desenvolvimento.
\end{abstract}

Figueiredo (1989) observa que ao negar e/ou ocultar a produção social e histórica do conhecimento, os profissionais das ciências agrárias acabam por aplicar tecnologias de soluções genéricas descartando a relevância das experiências locais para a construção de projetos que melhor se adequem as reais necessidades camponesas.

Já Sousa Santos (2006:94) argumenta que a “ tradição científica e filosófica ocidental” acaba por desvalorizar aquilo que não se conhece ou julga não importante e que sob uma característica epistemológica hegemônica leva ao desperdício da experiência que não se encaixa as necessidades reais camponesas, ou seja ao desprezar o conhecimento popular esse torna-se invisível e a invisibilidade ou o que não existe passa a ser considerado um resíduo de um passado remoto que bloqueia a plena realização da modernização e desenvolvimento de um projeto único direcionado para a monocultura.

Sob o aspecto da necessidade de exclusão do "resíduo", a extensão rural pública brasileira, por muitas décadas - a partir da década de 1960 -, seguiu e/ou ainda segue a tendência dominante do mercado sendo forte o discurso construído sobre a agricultura tradicional como necessária para a modernização e construção de um novo rural (CANUTO, 1984). Destaca-se, a título de exemplo, o papel do SENAR (Serviço Nacional de Aprendizagem Rural) que tem por objetivo formar trabalhadores rurais que estejam em consonância com os objetivos da agropecuária moderna latifundiária, gerando assim uma massa de trabalhadores subordinados as políticas institucionais dos empresários agrícolas (CAVALLET, 1999).

O modo de vida camponês não se enquadra ao modo de produção capitalista da agricultura patronal que busca a maximização do lucro. Sob essa tese, Chayanov apud Abramovay (1992) observa que na empresa capitalista há a tendência em se maximizar a lucratividade ampliando o capital investido. Já na empresa camponesa a maximização parte do objetivo fundamental de satisfazer as necessidades familiares.

Para a tendência da emergente e necessária modernização agrária, o modo camponês de maximização da necessidade da família entra em conflito com a maximização do lucro, que se tornou ao longo dos anos tão necessária para o rural brasileiro. A título de exemplo, em 2013 o setor agropecuário chegou a uma cifra de R \$424,5 bilhões segundo a Confederação da Agricultura e Pecuária do Brasil (CNA) em Valor Bruto da Produção (VBP). Para o mesmo período, o agronegócio alavancou cerca US\$ 100,7 bilhões em exportações, representando $22,80 \%$ do Produto Interno Bruto (PIB) nacional (CNA, 2014). Sob o termo agronegócio, Sauer (2008) destaca que:

[...] uso corrente do termo "agronegócio", no Brasil, expressa- ou deseja expressar- as atividades agropecuárias que utilizam técnicas de produção intensiva (mecanização química) e de escala, o que gera aumento da produção e da produtividade. Desde o início, o seu uso se deu em contraposição tanto à lógica latifundista, grandes extensões de terra utilizadas apenas como reserva de valor, como à da produção de subsistência, atividades agropecuárias de menor escala e com menos capital investido, ou seja, produtores "menos eficientes" e não plenamente, ou competitivamente, integrados ao mercado.

A dificuldade de políticas públicas para o fortalecimento da agricultura familiar e camponesa acaba por esbarrar em fatos e valores tão expressivos. Porém, Tepicht apud Abramovay (1992) verifica que "[...] a família camponesa cumpre [...] a função importante de permitir a oferta de produtos agropecuários a preços inferiores aos das grandes empresas". Buainain (2003) em seu artigo intitulado Agricultura Familiar e o Novo Mundo Rural apresenta um dado relevante que representa bem a força da agricultura familiar na sociedade agrária brasileira: dos $100 \%$ dos estabelecimentos rurais existentes no Brasil, 85,2\% são 
classificados como de trabalho "familiar". Já Kageyama et.al. apud Hoffmann (2014) destaca que a agricultura familiar foi responsável por $52 \%$ do valor da produção nacional agropecuária para o triênio 20062009 (média anual).

Apesar de uma boa representatividade para a sociedade brasileira, classificar a própria agricultura camponesa em "familiar" gera discussões. Segundo Wolf apud Neves (1997) a relação do produtor camponês com o mercado inaugura a sua existência social ou o distingue de outros tipos de agricultores primitivos. Já Neves (1997) verifica que a crescente vinculação dos agricultores ao mercado - dada a necessidade da incorporação técnica ditadas pela racionalidade econômica e competitividade - confirma a necessidade de se realizar uma análise mercantil, que ao mesmo tempo limita o entendimento da produção social através de estudos que desconsideram as formas de objetivação do consumo classificado erroneamente como improdutivo pelo sistema capitalista.

Para tanto, Jan Douwe van der Ploug, professor da Universidade de Wageningen, Holanda, chega a definição de "recampesinização" como um processo contemporâneo de resistência da agricultura de base familiar se expressando como uma forma de luta e identidade diante da era da globalização, deixando claro que após o processo de modernização da agricultura - a partir da década de 1960 - já não se pode classificar de forma dual a agricultura camponesa e a patronal como sendo uma sob a plataforma e/ou sistema de produção atrasado e a outra altamente tecnológica respectivamente. Sob esse aspecto, Petersen et. al. (2009) observa que cada vez mais o camponês se insere na lógica tecno-econômica da modernização que coloca a agricultura de caráter familiar em posição de permanente e crescente dependência em relação ao mercado de insumos e produtos não havendo um novo dualismo e sim há uma nova conjuntura construída em uma lógica definida como "agricultura familiar empresarial" que retém a essência camponesa (centralidade do trabalho na família) não havendo interpretações empobrecedoras do mundo rural atual e sim uma compreensão mais matizada referente ao chamado "grau de campesinidade" da agricultura familiar.

Os conceitos se entrelaçam e a distinção entre camponês e agricultor familiar torna-se na sociedade contemporânea cada vez mais difícil em termos de classificação relacionada as técnicas de produção agrícola. Todavia um fator a ser discutido relaciona-se à similaridade dos conceitos em termos do fator trabalho. Resgatando os aspectos ocorrentes no Brasil, com relação ao fator agrário, evidencia-se o bloqueio ao acesso as terras para as massas de libertos e de imigrantes, tendo como resultado a insegurança da posse da terra que consequentemente elevava a disposição de mão de obra barata para os grandes latifundiários (BUAINAIN, 2003).

A trajetória histórica da "Lei de Terras" e do desenvolvimento do capitalismo para o meio agrário ao longo do século XX continuou e ainda continua tendo uma forte influência como fatores de exclusão social, onde há o princípio da desvalorização do trabalho camponês em relação a outros mercados, criando assim uma relação subalterna e dependente do camponês frente ao grande latifundiário. Sob o aspecto da não valorização do trabalho camponês, Tepicht (1973) verifica que “ [...] o 'pessoal' de uma exploração familiar camponesa fornece, para aumentar sua renda global, um adicional de trabalho, pago a um preço mais baixo e provocando a queda de seu 'pagamento' coletivo". A partir desta observação, destaca-se o seguinte pensamento: quanto maior o número de excluídos dos fatores de produção (capital, terra, tecnologias, crédito, etc.), maior será o número de indivíduos que estarão à disposição de vender a sua força de trabalho a qualquer nível de salários dentro do modo capitalista de produção agrícola.

Tentando uma forma alternativa para a melhoria da renda familiar, Buainain (2003) observa que no Brasil é crescente na população economicamente ativa rural a busca de empregos rurais não agrícolas fenômeno observado em larga escala a partir da década de 1980 - representando esses empregos não uma ampliação das oportunidades de trabalho e sim uma chance precária de sobrevivência. Stédile em seu livro intitulado "A Questão Agrária no Brasil" apresenta dados relevantes com relação a ocupação no rural brasileiro. Em seu manuscrito, um dado chama atenção: para cada três pessoas que residiam no meio rural brasileiro, duas estavam ocupadas em atividades agropecuárias e uma na prestação de serviços não agrícolas. Sob esse aspecto, Silva (1996) destaca que a prestação de serviços não agrícolas no rural brasileiro é destinado para os setores da indústria de transformação, comércio e construção civil num processo 
denominado por ele como "urbanização do meio rural brasileiro", em que há também exploração do trabalho através dos baixos níveis de salários pagos as pessoas tidas como não "capacitadas" e/ou não "instruídas".

A tendência para se construir uma sociedade agrária fortalecida parte do pressuposto de um projeto que contemple as unidades de produção familiares com apoio suficiente capaz de produzir uma renda total superior ao custo de oportunidade do trabalho (BUAINAIN, 2003).

Stédile apud Petersen et. al. (2009) defende que para o agrário brasileiro se deve construir uma base de projeto popular que contemple as mais diferenciadas formas de organização da produção agrícola sendo necessário a construção de novos paradigmas que orientem a produção em geral combatendo dois aspectos fundamentais: exploração do trabalho camponês pelas empresas e a degradação ambiental.

\title{
4. PANORAMA DA LUTA SOCIAL CAMPONESA NO BRASIL - ANOS 80, 90 E 2000
}

Um dos epicentros para o golpe militar foi a questão da reforma agrária, uma das bandeiras do governo João Goulart para realizar a chamada "Reforma de Base" (TAVARES, 2014). Passamos por um longo período ditatorial que começou em 1964 e se encerrou em 1985 com a redemocratização da sociedade através do presidencialismo, com eleições diretas. Para o período ditatorial, houve uma severa repressão aos movimentos sociais. Sob a ótica dos movimentos sociais agrários ocorrentes no período ditatorial, Carneiro (2010) destaca:

\begin{abstract}
Durante a ditadura militar no Brasil, o uso do termo "camponês" poderia ser suficiente para desencadear prisões, torturas e assassinatos [...] foi a partir dos anos 1950 que os movimentos passaram a generalizar o uso do termo "camponês" no país, revestindo demandas locais em propostas políticas vinculadas a um projeto nacional. A palavra reunia ampla gama de categorias - lavradores, trabalhadores rurais, meeiros, foreiros, agricultores familiares, pequenos proprietários, posseiros-, articulando reivindicações diversas: direitos trabalhistas, acesso à previdência social, direito à posse, reforma agrária, etc. Assim, carregava um significado simbólico e um sentido político. Foi justamente esse sentido político do termo "camponês" que passou a ser combatido, não apenas pelos agentes da repressão militar, como também por latifundiários e seus capangas.
\end{abstract}

Silva (2006) observa que a expansão das Ligas Camponesas antes do golpe militar - principalmente no Nordeste - sob a liderança de Francisco Julião, contribuiu para a popularização do termo camponês que acabou por significar "aquele que luta pela terra". Ao se encerrar o período ditatorial, o termo camponês passa a significar "trabalhador rural" sendo mais abrangente. Pelo panorama exposto, observa-se que o período ditatorial teve políticas agrárias direcionadas ao mercado agroindustrial nascente, ampliando a exclusão da participação do camponês no processo de modernização do setor agrário brasileiro.

Com a abertura "lenta e gradual" do último governo militar -1979/85, João Baptista de Oliveira Figueiredo - a sociedade passa por uma efervescência de movimentos políticos e sociais nas esferas urbana e rural. Destaca-se, para o período, o movimento político das "Diretas Já", a explosão e/ou nascimento de partidos políticas como o PT, PSDB, PMDB, PSC, dentre tantos outros e o surgimento do movimento agrário de acesso à terra por parte do agora então "trabalhador rural".

Dificilmente não se entrará no consenso que, no início da década de 1980 há um movimento emergente de luta social para o rural brasileiro, o movimento dos chamados "sem-terra" e que segundo Santos (2002) são lutas sociais inesperadas, em especial se comparado ao diagnósticos típico dos clássicos, Lênin, Kautsky e Engels, que eram céticos com relação a manutenção do modo de vida camponês frente ao capitalismo na agricultura e sua possível organização política na busca de reivindicações sociais para sua classe. O movimento social dos trabalhadores sem-terra nasce oficialmente em janeiro de 1984 na cidade de Cascavel, estado do Paraná, mas sua "gestação" ocorre nas primeiras reuniões realizadas entre 1978 e 1983 (FERNANDES, 2000). Sua primeira denominação foi Movimento de Trabalhadores Rurais Sem Terra (que permanece até hoje). Porém a expressão "trabalhadores rurais" caiu em desuso dentro do próprio movimento 
dada a fundação da Via Campesina, a partir da década de 1990, que trouxe a expressão camponês como agente social de representação e voz nos documentos de reivindicação do próprio movimento. Fernandes (2005) ressalta que a expressão camponês fortaleceu e ampliou a identidade do próprio MST, destacando que "o movimento camponês não existe sem o território do campesinato, adquirindo o MST uma configuração de luta socioterritorial".

A redemocratização dos anos 80 é marcada pela emergência de políticas modificadoras da realidade das classes sociais excluídas, tendo como exemplo marcante a classe dos trabalhadores rurais sem acesso à terra. Santos (2002) observa que o MST deste então - como movimento de inclusão social da classe camponesa - enfrenta o desafio de ter como base "os mais pobres entre os pobres do campo", representado por grupos sociais de ocupação episódica, sem moradia definida, sem acesso a escolaridade e facilmente vítimas de manipulações políticas da classe dominante. Como bandeira social, Stédile em seu livro intitulado "A questão Agrária no Brasil" nos apresenta os objetivos gerais da reforma agrária proposta pelo MST desde a sua fundação: Eliminar a pobreza; Combater a desigualdade social; Garantir trabalho, educação e distribuição de renda no campo; Garantir a soberania alimentar nos mercados locais; Garantir a participação igualitária das mulheres nas decisões de uso da terra; Manter e preservar a biodiversidade vegetal, animal e cultural de cada região; Garantir a permanência da juventude no campo através de ações promotoras da renda, de educação, moradia e lazer.

Para tanto, no final da década de 1980, surge uma esperança de "vez e voz" do movimento MST com relação ao acesso à terra no Brasil, a Carta Constitucional de 1988 por representar um caráter maior de cidadania, conforme expresso em seu texto de preâmbulo (BRASIL, 2014):

Nós, representantes do povo brasileiro, reunidos em Assembleia Nacional Constituinte para instituir um Estado Democrático, destinado a assegurar o exercício dos direitos sociais e individuais, a liberdade, a segurança, o bem-estar, o desenvolvimento, a igualdade e a justiça como valores supremos de uma sociedade fraterna, pluralista e sem preconceitos, fundada na harmonia social e comprometida, na ordem interna e internacional, com a solução pacífica das controvérsias, promulgamos, sob a proteção de Deus, a seguinte Constituição da República Federativa do Brasil.

Porém, de acordo com Stédile (2013), a constituição de 1988 em seu inciso II, artigo 185 apresenta o termo "propriedade produtiva" como base de avaliação para possíveis desapropriações rurais gerando controvérsias em relação ao próprio conceito, pois a expressões "propriedade produtiva", "terra produtiva" e/ou "imóvel rural produtivo" são utilizados erroneamente, representando dificuldades de ordem legal, agronômica e operacional por identificar a gleba, o estabelecimento agropecuário ou o imóvel rural sob o caráter " utilização", não importando se a propriedade rural está sendo utilizada sob a fração mínima ou máxima do seu espaço territorial. A nova constituição acaba por complicar qualquer tentativa séria de mudança na estrutura fundiária brasileira. Porém, discussões sociais relevantes com relação à questão agrária vem à tona na nova constituição: há pela primeira vez na história um capítulo especial sob reforma agrária; se traz para o texto a explicação da função social; cria-se o mecanismo da perda sumária das glebas para aqueles que cultivam psicotrópicos; determina-se a reavaliação de todos os incentivos fiscais; dispõe sobre a demarcação de terras públicas dentro de cinco anos e obriga, dentro de três anos, a revisão das concessões de terras públicas com áreas superiores a três mil hectares realizadas até o ano de 1987. Sob os parâmetros "vez e voz", a massa de trabalhadores camponeses vê em sua própria luta de classe a verticalização nas discussões pertinentes aos seus direitos e deveres, não sendo realizado qualquer tipo de discussão com as representações populares, sendo as medidas e ações promotoras para o "desenvolvimento social rural camponês" decididas no alto escalão político (STÉDILE, 2013).

Dada a frustação relacionado ao aspecto da não efetivação da reforma agrária pela assembleia constituinte de 1988, Navarro (1996) aponta que para o período, as ações do MST passam a ter um caráter maior de confronto entre camponeses e latifundiários em que a ideologia do movimento deixa de ser "Terra para quem nela trabalha" e passa a ser "Ocupar, resistir, produzir". O conflito em si passa a corroer a própria legitimidade do MST e abre um novo precedente de discussões com relação a necessidade de se efetivar a reforma agrária. 
Comparato (2001) em seu manuscrito intitulado “A Ação Política do MST" traz a título de exemplificação o episódio do massacre ocorrido em Eldorado dos Carajás em que o governo do então presidente Fernando Henrique Cardoso buscou tendênciar a opinião pública a perceber o MST como movimento criminoso que realizava suas ações fora da lei, tentando descaracteriza-lo como movimento social. Iris Rezende, então ministro da justiça, na época chegou a declarar que "polícia e fazendeiros têm de andar de mãos dadas para cumprir mandados judiciais", ou seja, o próprio estado buscava legitimar o poder do latifundiário rural. Comparato (2001) também observa que em um país de dimensões continentais como o Brasil, em que a maioria dos partidos políticos tem por tradição serem representantes fracos e regionais, outros atores políticos como o Movimento dos Trabalhadores Sem-Terra, não pode ser negligenciado. As articulações das ações do MST recaem sobre uma nova habilidade a de formar alianças com vários segmentos da sociedade civil.

Chega-se ao século XXI, e o então aguardado governo do Partido dos Trabalhadores ascende ao poder, através do ex-sindicalista Luís Inácio Lula da Silva, que sempre levantou a bandeira da necessidade da realização da reforma agrária como pressuposto de inclusão social para o rural brasileiro. Porém, conforme verifica Engelmann (2012), no decorrer do governo Lula as propostas de mudanças sociais permaneceram apenas nas promessas de campanha. Stédile (2005) destaca duas propostas eleitorais do governo PT para o setor agrário brasileiro, a de $1989 \mathrm{em}$ que Lula perde as eleições para o candidato Fernando Collor e a de 2002 em que saí vitorioso. Em 1989 a proposta petista era a de propor a realização da reforma agrária através da proposta de eliminação da concentração da terra e desenvolvimento da agricultura e da economia, ou seja, "[...] romper o monopólio da terra e lançar as bases de um padrão de desenvolvimento para toda agricultura e toda a economia brasileira" (Programa Agrário do PT, 1989, apud STÉDILE, 2005, p.181.).

Já em 2002 sob a aliança do empresariado em geral, o discurso mais "fervoroso" de 1989 muda de sentido com relação à proposta de reforma agrária, passando o PT a considerar a emergência de uma política para o desenvolvimento rural baseada em desapropriação de terras improdutivas; conciliada a produção de alimentos para combate à pobreza e a recuperação dos assentamentos, com infraestrutura social, econômica, assistência técnica e créditos agrícolas (Programa Agrário da Campanha Presidencial do PT, 2002, apud STÉDILE, 2005). A partir de uma leitura das duas propostas, Engelmann (2012) verifica que a reforma agrária brasileira, para o início do século XXI, fundamenta-se em propostas relacionadas ao programa de criação de assentamentos que está restrito a áreas improdutivas ou ilegais (griladas ou com trabalho escravo) não significando uma democratização fundiária, permanecendo o "mais do mesmo", através de uma política compensatória de assentamentos para o chamado "desenvolvimento capitalista no campo", onde foi criado dois modelos agrícolas: um modelo relacionado ao camponês, com políticas de assentamentos e incentivos para que o mesmo participe do processo de construção da agricultura familiar com a produção de alimentos e/ou matéria prima para os vários programas de redução e combate à pobreza no campo (PRONAF, Programa de Aquisição de Alimentos, Biodiesel, dentre outros) e outro modelo de incentivo e fortalecimento do agronegócio mantendo o sistema hegemônico do latifúndio e da monocultura para a exportação.

Além da terra, verifica-se então a necessidade emergente de um programa político de reforma agrária para a população camponesa que apresente propostas sociais que busquem o padrão contrário ao que o mercado exige, sendo como definiu Engelmann (2012): “[...] uma reforma agrária popular anticapitalista de enfrentamento ao agronegócio, voltado para a pequena agricultura e para a produção social cooperativa”. A luta deve persistir para que se consolide de fato, uma reforma agrária mais inclusa dos saberes e da participação popular baseada num novo modelo promotor da democracia de acesso a propriedade da terra e da igualdade de oportunidades com relação ao uso dos recursos ambientais, priorizando sempre a produção de alimentos promotores da segurança alimentar da sociedade brasileira.

\section{CONSIDERAÇÕES FINAIS}

Conforme apresentado, a questão da reforma agrária não segue a simples corrente da distribuição de terra. Há todo um processo de discussão da real necessidade da efetiva construção social para o camponês, que por tanto tempo foi deixado de lado do processo de construção do "novo" rural brasileiro. Hoje a reforma agrária necessita seguir uma corrente de pensamento e ação que valorize o modo de produção e

Persp. online: hum. \& sociais aplicada., Campos dos Goytacazes, 15 (6), 01-13, 2016 
reprodução camponês, não sendo mais necessário "impor o que é melhor" e sim entender toda uma dinâmica relacionada ao modo de vida camponês, para que haja o pleno atendimento das reais necessidades sociais e /ou regionais camponesas, pois as questões sociais rurais são por muitas vezes heterogêneas e complexas.

\section{REFERÊNCIAS BIBLIOGRÁFICAS}

ABRAMOVAY, Ricardo. Paradigmas do capitalismo agrário em questão. São Paulo, HUCITEC, 1992.

AQUINO, Rubim S.L. Fazendo a História: A Europa e as Américas no século XIX e XX. Rio de Janeiro: Ao livro Técnico, 1986.

ARAUJO, Tania Bacelar. Governo FHC prioriza o setor financeiro. Jornal Sem Terra, São Paulo, Fev, 1998.

BRASIL. Constituição da República Federativa do Brasil De 1988. Presidência da República, Casa Civil. Acesso em 02 de junho de 2015. Disponível em: https://www.planalto.gov.br/ccivil_03/Constituicao/Constituicao.htm 2014

BUAINAIN, Antônio Márcio; ROMEIRO, Ademar R.; GUANZIROLI, Carlos. Agricultura Familiar e o Novo Mundo Rural. Sociologias, Porto Alegre, ano 5, n 10, jul/dez 2003, p. 312-347.

BUARQUE, Cristovam. O colapso da modernidade brasileira: e uma proposta alternativa. 2. ed. Rio de Janeiro: Paz e Terra, 1991.

CARdoso, C. F. S. As Estruturas Agrárias da América Latina na Época Colonial: Tentativa de Síntese Interpretativa. História: Questões e Debates, Curitiba, v. 03, n.04, p. 11-26, 1982.

CARNEIRO, Ana; CIOCCARI, Marta. Retrato da Repressão Política no Campo - Brasil 1962-1985 Camponeses torturados, mortos e desaparecidos. Brasília: MDA, 2010.

CNA. Agronegócio: Balanço 2013, Perspectiva 2014. Confederação da Agricultura e Pecuária do Brasil. Acesso em: 28 de maio de 2015. Disponível em: http://www.canaldoprodutor.com.br/sites/default/files/balanco_CNA_2013_web.pdf

CANUTO, J. C. Capital, tecnologia na agricultura e o discurso da EMBRATER. Santa Maria: UFSM, 1984. 137p. [Dissertação de Mestrado].

CAVALLET, José Valdo. A formação do engenheiro agrônomo em questão: a expectativa de um profissional que atenda as demandas sociais do século XXI. Tese (doutorado). Curso de Pós-Graduação em Educação, Universidade de São Paulo - FEUSP, São Paulo, 1999.

COMPARATO, B.K. A ação política do MST. Dissertação de Mestrado. São Paulo, Faculdade de Filosofia, Letras e Ciências Humanas (FFLCH) da USP, 2001.

DIAS, M. M. As ONGs e a construção de alternativas para o desenvolvimento rural: um estudo a partir da Assessoria e Serviços a Projetos em Agricultura Alternativa (AS-PTA). 199 f. Tese (Doutorado). Curso de Pós-Graduação em Desenvolvimento, Agricultura e Sociedade, Universidade Federal Rural do Rio de Janeiro, Rio de Janeiro, 2004.

ENGELMANN, Solange I.; GIL, Aldo Duran. A questão agrária no Brasil: a política agrária do governo Lula e a relação com o MST. Revista Eletrônica do CEMOP - No 02 - setembro de 2012. Disponível em: www.memoriaoperaria.org.br - ISSN 2238-443X

FAUSTO, Boris. História do Brasil $-\mathbf{2}^{\mathbf{0}}$ ed. São Paulo: Editora da Universidade de São Paulo: Fundação Educação do Desenvolvimento da Educação, 1995.

FERNANDES, Bernardo Mançano. A formação do MST no Brasil. Petrópolis: Vozes, 2000.

"Movimentos socioterritoriais e movimentos socioespaciais" em OSAL (Buenos Aires: CLACSO) Vol. 16, Janeiro-abril, 2005. 
FIGUEIREDO, V. Produção social da tecnologia. São Paulo: EPU, 1989.54p. (Temas Básicos de Sociologia e Política).

FREIRE, Paulo. Educação como prática da liberdade. 17. ed. Rio de Janeiro: Paz e Terra, 1986.

FURTADO, Celso. Formação econômica do Brasil. Rio de Janeiro: Fundo de Cultura, 1959.

GARCIA, Paulo. Terras devolutas; defesa possessória, usucapião, regime Torrens. Ação discriminatória. Belo Horizonte: Edição da Livraria Oscar Nicolai, 1958, p. 22.

GERMANI, Guiomar Inez. GeoTextos, vol. 2, n. 2, 115-147, 2006.

GRAZIANO DA SILVA, José. Estrutura Agrária e produção de subsistência na agricultura brasileira. São Paulo: Hucitec, 1980.

. A nova dinâmica da agricultura brasileira. Campinas: UNICAMP,1996.

GUIMARÃES, Alberto Passos. Quatro séculos de latifúndio. 4ª ed. Rio de Janeiro: Paz e Terra, 1977.

HOFFMANN, Rodolfo. A agricultura familiar produz $\mathbf{7 0 \%}$ dos alimentos consumidos no Brasil? Nota Técnica. Segurança Alimentar e Nutricional, Campinas, 21(1):417-421, 2014.

HOLANDA, Sérgio Buarque. Raízes do Brasil. 10. ed. Rio de Janeiro: J. Olympio, 1976.

IGLÉSIAS, Francisco et. al. O Brasil Monárquico: Reações e Transações, v.3. $7^{\mathbf{0}}$ Ed. Rio de Janeiro, Bertrand Brasil, 2004.

LÊNIN, Vladimir Ilitch. O desenvolvimento do capitalismo na Rússia. Tradução: José Paulo Netto. São Paulo, Abril Cultural, 1982

LIMA, Graziela F. Buscarin. Evolução histórica da propriedade territorial no Brasil. Dissertação de Mestrado em Direito Civil. São Paulo: Faculdade de Direito da USP, 2002

LIMA, Ruy Cirne. Pequena história territorial do Brasil: sesmarias e terras devolutas. 4.ed. Brasília: ESAF, 1988, capítulo 1.

MÜLLER, Geraldo. Complexo agroindústrial e modernização agrária. São Paulo: Hucitec, 1989.

NAVARRO, Zander. Política, protesto e cidadania no campo. Porto Alegre: Editora da Universidade, 62$105,1996$.

NEVES, Delma Pessanha. Agricultura Familiar e Mercado de Trabalho. Estudos Sociedade e Agricultura, 8 de Abril de 1997 (7-24).

OLIVEIRA, Alexandra Maria de. A Participação do Banco Mundial no Mercado de terras no Brasil e no mundo. Fortaleza: Edições UFC, 2012. 192p.

OLIVEIRA, Ariovaldo Umbelino de. A longa marcha do campesinato brasileiro: movimentos sociais, conflitos e reforma agrária. Estudos Avançados 15 (43), 2001.

PETERSEN, Paulo et. al. Agricultura familiar camponesa na construção do futuro. Rio de Janeiro: ASPTA, 2009.

PLOEG, J.D. van der. Camponeses e Impérios Alimentares. Porto Alegre: UFRGS, 2008.

PRADO JUNIOR, Caio. História Econômica do Brasil. 21 ${ }^{\text {a }}$ ed. São Paulo: Brasiliense, 1978.

SANTOS, Boaventura de Sousa. Produzir para viver. Rio de Janeiro: Civilização Brasileira, 2002, p. 189-232.

SAUER, Sérgio. Agricultura Familiar versus agronegócio: a dinâmica sociopolítica do campo brasileiro. EMBRAPA Informação tecnológica, 2008

SILVA, José Graziano da et.al. Tecnologia e Campesinato: O caso brasileiro. Revista Economia Política, vol.3, nº 4, outubro-dezembro de 1983. 
São Paulo: Seade/bolso, 1995, p.197-222.

SILVA, S. Agricultura e Capitalismo no Brasil. Contexto, São Paulo, (1): 23-42, nov.1976

SOUSA SANTOS, B. A gramática do tempo para uma nova cultura política. São Paulo: Cortez, 2006. 511p. (Col. Para Um Novo Senso Comum, 4).

STÉDILE. João Pedro. A questão agrária no Brasil: Programas de reforma agrária 1946-2003. São Paulo: Expressão Popular, 2005.

. A Questão Agrária do Brasil: Debate sobre a situação e perspectivas da reforma agrária na década de 2000. $1^{\mathbf{0}}$ Ed. São Paulo: Expressão Popular, 2013.

A questão Agrária no Brasil: O Debate na década de 1990. Editora Expressão Popular, $2^{\circ}$ Edição. São Paulo, 2013.

TAVARES, Flávio. 1964: o Golpe. Porto Alegre, RS: L\&PM, 2014

TEIXEIRA DA SILVA, F. C. Brasil-Colônia, 1698: Seca, fome e rebelião popular. Convergência Lusiada, Rio de Janeiro, v. 15, p. 76-86, 1998

TEPICHT, J. Marxisme et Agriculture: Le Paysan Polonais. Armand Colin, Paris, 1973. 